\title{
Modeling and Analysis of Axial Dynamics of Cable Arrangement Device Based on MATLAB
}

\author{
Fankai KONG ${ }^{\text {a, }}$, Yucai PAN ${ }^{\text {a }}$, Jiawei ZHAO ${ }^{\text {a }}$, Nan ZHANG ${ }^{\text {a }}$, Zhenyang WANG ${ }^{\text {a }}$ \\ and Huaqiu DING ${ }^{\mathrm{a}}$ \\ ${ }^{a}$ College of Mechanical and Electrical Engineering, Harbin Engineering University, \\ Harbin, Heilongjiang Province 150001, China
}

\begin{abstract}
Aiming at the current insufficient dynamic analysis of the cable arrangement device, the axial dynamics analysis of the cable arrangement device is carried out in combination with the force characteristics of the cable arrangement device. The axial dynamic model of cable arrangement device is established by using spring-damping model, and the dynamic equation is established by using Lagrange equation. The influence of system parameters of cable arrangement device on axial first-order natural frequency is analyzed by numerical method. By fitting and loading the external excitation of the cable arrangement device, the axial dynamic response of the cable arrangement device under different axial forces is obtained. Through numerical results, the influence laws of the position and mass of the traveling mechanism and the support stiffness of the lead screw on the axial first-order natural frequency are obtained, It is found that the axial displacement of the cable arrangement device under axial force is very small, and the cable arrangement device has strong retention of dynamic characteristics. The results have certain guiding significance for the structural design and application environment of cable arrangement device.
\end{abstract}

Keywords. Full ocean depth geological winch, cable arrangement system, dynamic analysis, dynamic performance, finite element analysis

\section{Introduction}

Full sea depth geological winch system is the key marine engineering equipment used for deep sea operation. And the cable rower is the core component to ensure that the cable is neatly arranged on the cable storage reel.

At present, however, most of the researches on cable arrangement device focus on the design and analysis of arrangement structure scheme, structural strength and control scheme. Miao $\mathrm{Hu}$ and Minjing Zhu designed a cable arrangement device driven by trapezoidal thread screw. It provides a reference for the structural design of cable arrangement device [1]. Xiaorong $\mathrm{Xu}$ and Gang $\mathrm{Xi}$ used ANSYS to analyze the strength of the cable arrangement device at different positions of the guide wheel under two working conditions of navigation and towing, which provided a reference for the strength analysis and verification of the same type of cable arrangement device [2].

\footnotetext{
${ }^{1}$ Fankai Kong, College of Mechanical and Electrical Engineering, Harbin Engineering University, Harbin, Heilongjiang Province 150001, China; E-mail: kongfankai @hrbeu.edu.cn.
} 
In the aspect of dynamic research on lead screw feeding system, Gomand and Kestelyn studied the influence of axial deformation of lead screw on the dynamic and static response of the system [3]. YongZhou studied the influence of table position and workpiece mass change on the first three free vibration modes [4]. Lei Wang proved that the dynamic coupling relationship between the feed shafts would cause structural deformation of the feeding system [5]. However, it can be found that there is little research on the axial characteristics of the feeding part of the cable arrangement device.

In view of the present research situation, this paper takes the axial dynamic characteristics of the cable arrangement device as the research object, establishes the dynamic model and dynamic equation of the cable arrangement device, and compiles the program by MATLAB. The influence laws of the position and mass of the traveling mechanism and the support stiffness of the lead screw on the axial first-order natural frequency of the cable arrangement device are analyzed, and the function of the external load on the cable arrangement device is fitted by MATLAB, and the influence of the external load on the dynamic characteristics of the cable arrangement device is analyzed. Provide guidance for the structural design and use environment of the cable arrangement device.

\section{Establishment of Axial Dynamic Model of Cable Arrangement Device}

According to the related theory of dynamics, the spring-damping equivalent system is used to treat the axial stiffness and damping of the bearing and the lead screw equivalently, and the axial dynamic model of the transmission part of the cable arrangement device is established, as shown in figure 1 below [6].

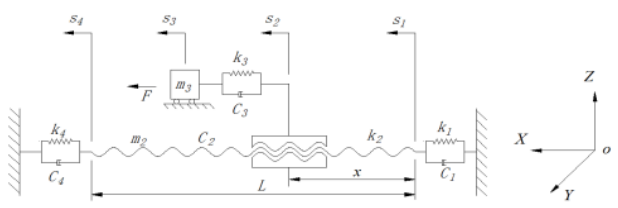

Figure 1. Dynamic model of transmission part of cable arrangement device.

The dynamic equation of the cable arrangement device in this paper is derived by Lagrange equation. After calculation, it can be obtained from Lagrange equation. Organize into matrix form as follows:

$$
[M]\{\ddot{s}\}+[C]\{\dot{s}\}+[K]\{s\}=\{Q\}
$$

\section{Analysis of the Influence of Cable Arrangement Device Parameters on Natural Frequency}

This paper quantitatively analyzes the effects of the mass of the travel mechanism, the axial stiffness of the bearings, and the relative position of the travel mechanism on the screw on the first-order inherent frequency of the drive system dynamics model of the cable arrangement device. When the undamped system vibrates freely, the characteristic equation is: 


$$
\left([K]-\omega^{2}[M]\right)\{u\}=0
$$

According to the formula (2), a solution program is written by using the ode function in MAELAB, and the natural frequencies of each order of undamped system of cable arrangement device can be obtained by bringing in the relevant parameters.

\subsection{Influence of Relative Position of Traveling Mechanism on Frequency of Cable Arrangement Device}

The parameters of the dynamics model of the cable rower can be obtained [7-8]. And then keep other parameters constant, the influence of the change of nut position relative to lead screw on the frequency of cable arrangement device is analyzed. It can be seen from figure 2. The results showed the same pattern of variation as in the literature [9].



Figure 2. The law of first-order natural frequency under the change of nut position.

The reason why the lowest frequency position is not at the midpoint of the screw is that the axial stiffness of the support bearings at both ends of the screw is different. The significance of studying the influence of position change on the first-order natural frequency lies in that when considering the position of the traveling mechanism, the traveling mechanism should be arranged as far as possible to arrange cables at the part with strong rigidity on the right side, so as to improve the cable arrangement accuracy.

\subsection{Influence of Traveling Mechanism Mass on Frequency of Cable Arrangement Device}

It is assumed that the traveling mechanism is in the middle position of the lead screw and kept other parameters constant, set the walking mechanism mass $m_{3}$ to $300 \mathrm{~kg}$ to $900 \mathrm{~kg}$, and the changes are shown in figure 3 below. 


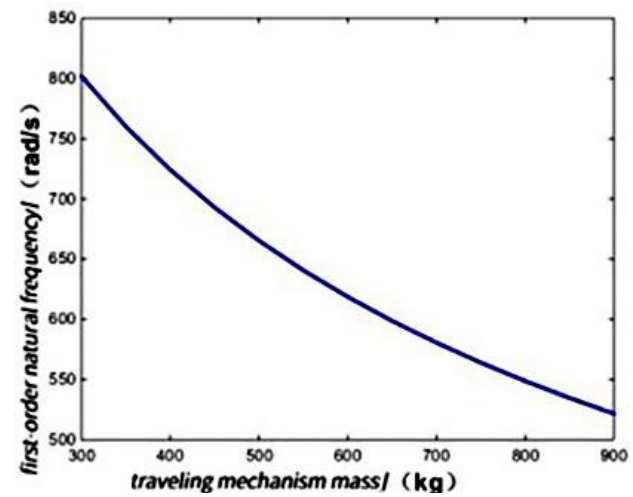

Figure 3. Influence of traveling mechanism mass on first-order natural frequency.

It can be seen from the above figure that the first-order natural frequency decreases with the increase of the mass of the traveling mechanism of the cable arrangement device, with the reduction range reaching $34 \%$. Therefore, Therefore, when designing the travel mechanism, the mass of the travel mechanism can be reduced.

\subsection{Influence of Stiffness on Frequency of Cable Arrangement Device}

Respectively, keeping other parameters constant and position the nut to the middle of the screw. Analyze the effect of the variation of stiffness $k_{1}, k_{3}, k_{4}$ on the first-order intrinsic frequency respectively. Set the variation of the three stiffnesses to $100000 \sim 9000000000 \mathrm{~N} / \mathrm{m}$. The analysis results are as shown in figure 4 below.

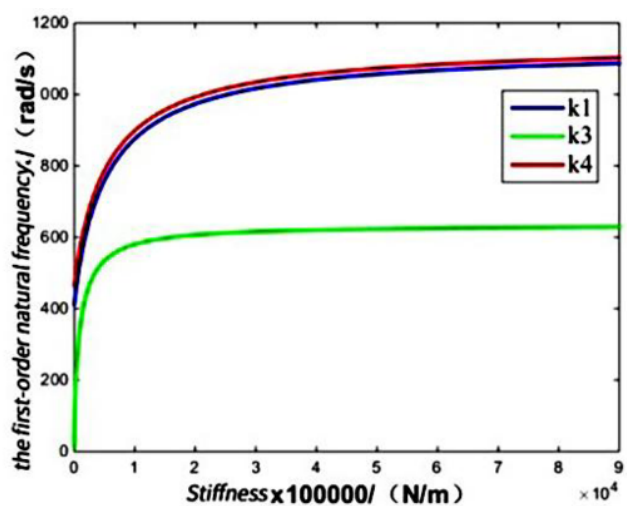

Figure 4. Stiffness. $k_{1}, k_{3}, k_{4}$ Influence on the first-order natural frequency.

As can be seen from the figure, the change trend of stiffness of left and right bearings to the first-order natural frequency is approximately the same. The effect of bearing axial stiffness on the variation of the first-order inherent frequency tends to level off after reaching $3 \times 10^{9} \mathrm{~N} / \mathrm{m}$. The stiffness of the nut and screw combination surface has a large effect on the axial first-order inherent frequency until it reaches 
$1 \times 10^{9} \mathrm{~N} / \mathrm{m}$, which can cause the first-order inherent frequency to increase rapidly, and then the change tends to level off.

With the three variations of stiffness set to $100000 \sim 9000000000 \mathrm{~N} / \mathrm{m}$, at the same stiffness, the axial stiffness of the left and right bearings makes a great contribution to the axial first-order natural frequency. The significance of studying the influence of various stiffness changes on the first-order natural frequency can provide reference for the selection of supporting bearings and the design of the joint surface between nuts and lead screws. To improve the axial first-order natural frequency, according to the method of calculating each stiffness, we can choose bearings with a large number of balls and bearings with a large effective length of balls, and you can also appropriately increase the axial pretightening force of bearings.

\section{Axial Dynamic Response Analysis Of Feeding System of Cable Arrangement Device}

\subsection{Influence of Damping Ratio on Dynamic Response Under Steady Load}

Because the influence of damping on the dynamic response of the system cannot be predicted in advance, it is necessary to analyze the dynamic response changes of the system under different damping ratios. The input load of the system is $5000 \mathrm{~N}$, and the first and second modal damping values are $0.01,0.02,0.03$ and 0.04 , respectively. And the results are as shown in figure 5 below.

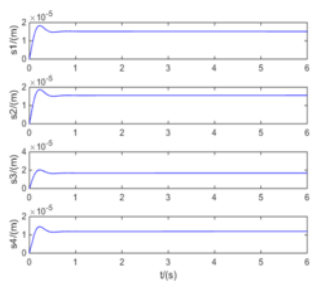

(a) $\xi_{1}=\xi_{2}=0.01$

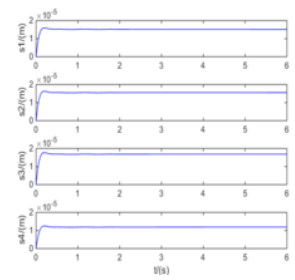

(b) $\xi_{1}=\xi_{2}=0.02$

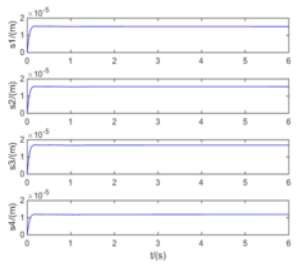

(c) $\xi_{1}=\xi_{2}=0.03$



(d) $\xi_{1}=\xi_{2}=0.04$

Figure 5. Dynamic response of different damping under steady load.

It can be seen from the above figure that, when the damping ratio is fixed, the response changes of the system under steady load increase in a short time and then decrease slightly, and then reach a stable value after slight fluctuation. When the damping ratio is 0.01 , the maximum axial displacement is only $0.02 \mathrm{~mm}$. With the increase of damping ratio, the axial response of the system becomes smaller and smaller after reaching the maximum.

\subsection{Influence of Damping Ratio on Dynamic Response Under Fluctuating Load}

We choose case $\xi_{1}=\xi_{2}=0.01$ to analyze the axial dynamic response of the system under fluctuating load, as shown in figure 6 below. 


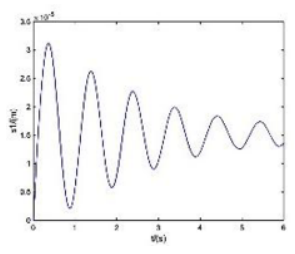

(a) $S_{1}$

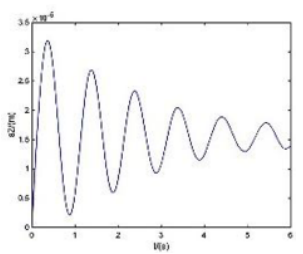

(b) $S_{2}$

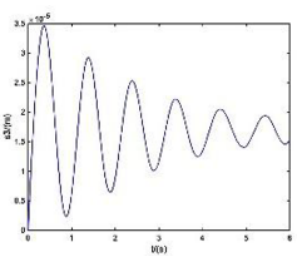

(c) $S_{3}$



(d) $S_{4}$

Figure 6. System dynamic response under fluctuating load.

It can be seen from the above figure that the dynamic response change of the system under the action of fluctuating load is consistent with the change of load. The maximum response of the system occurs at $S_{3}$, the maximum is $0.035 \mathrm{~mm}$

Through the above analysis, it is found that the greater the damping ratio, the smaller the fluctuation of the system response. Whether under steady load or fluctuating load, the response of the system is maximum at both $S_{3}$, and the maximum axial response is only $0.035 \mathrm{~mm}$. This shows that the axial response of the designed cable arrangement device under the action of cable load can ensure the accuracy of cable arrangement.

\section{Summary}

Come to the following conclusions. (1) The moving range of the traveling mechanism should be arranged at the position with strong axial stiffness of the cable arrangement device.

(2) The mass of the traveling mechanism has a great influence on the first-order natural frequency. When it is increased from $300 \mathrm{~kg}$ to $900 \mathrm{~kg}$, the first-order natural frequency decreases by $34 \%$.

(3) The stiffness of the support spring and the stiffness of the joint surface can make the first-order natural frequency increase rapidly within a certain range, but the influence decreases gradually after exceeding a certain range.

(4) Under steady load, when the damping ratio is 0.01 , the axial displacement of the cable arrangement device is the largest, which is only $0.02 \mathrm{~mm}$; Under fluctuating load, the maximum axial displacement is $0.035 \mathrm{~mm}$; And the larger the damping ratio, the smaller the fluctuation of the axial response of the system.

\section{Acknowledgements}

The paper is funded by National key research and development program funded projects: (2018YFC0309004). This paper is financially supported by High-tech ship scientific research project in 2018 (ministry of industry and information technology packing letter [2018] no. 473 and emergency evacuation chute system development, ministry of industry and information technology packing letter [2017] no. 614). 


\section{References}

[1] Miao HU, Minjing Z. Design of Constant-Tension Deploying and Retracting Winch for Optic-Electrical Composite Cable of ROV. Optical Fiber \& Electric Cable and Their Applications. 2018 Mar;164(8): 427-433.

[2] Xiaorong XU, Gang XI, Ramp N, et al. Analysis on strength of towing winch based on finite element method. Mine Warfare \& Ship Self-Defence. 2018 Feb; 26(1): 28-32+5.

[3] J Gomand, Kestelyn X, Barre P J. Dual-drive gantry stage decoupling dynamic analysis based on a coupling model. Electro Motion. 2008 Feb.;15(2): 94-98.

[4] Zhou Y, Peng FY, Cao XH. Parameter sensitivity analysis of axial vibration for lead-screw feed drives with time-varying framework. Mechanics. 2011 Oct; 17(5): 523-528.

[5] Wang L, Liu HT, Yang L, Zhang J, Zhao WH, Lu BH. The effect of axis coupling on machine tool dynamics determined by tool deviation. International Journal of Machine Tools and Manufacture. 2015 Jan; 88(1):71-81.

[6] Wang YQ, Zhang CR, Zhai P. Quantitative change rule for axial first-order natural frequency of ball screw feed drive system. Shenyang Gongye Daxue Xuebao/Journal of Shenyang University of Technology. 2013 Jan; 35(1): 58-62.

[7] Li WM. Rigidity calculation of axial position preload taper roller bearings. Bearing, 2004 May; 2004(05): 1-3.

[8] Zhang WK,Zheng XG,Tang QS, Li P, Bai WZ. Research on dynamic model of ballscrew with largelead in feed system. Science Technology and Engineering. 2013 Oct; 13(29): 8721-8724+8728.

[9] Huang J, Yuan J, Wang Z. Dynamic modelling of a dual-drive system and its dynamic characteristics. Zhendong yu Chongji/Journal of Vibration and Shock. 2017 Sep; 36(18): 148-153 +163. 